\title{
Acceptance and utilization of HIV testing among the youth: a cross-sectional study in Techiman, Ghana
}

\author{
Bernard YA Asare ${ }^{1}$, Henrietta Y Yeboaa ${ }^{2}$, Bismark Dwumfour-Asare ${ }^{3}$
}

1. Research Web Africa, P. O. Box 2591, Sunyani B/A, Ghana; asiamahyeboah2006@yahoo.com

2. Ghana Co-operative Credit Unions Association, P. O. Box 320, Abesim-Sunyani B/A, Ghana; henriattayeboaa@gmail.com

3. Department of Environmental Health and Sanitation Education, College of Agriculture Education, University of Education, Winneba, Asante-Mampong, Ghana; dwumfourasare@gamil.com

\begin{abstract}
Background: In Ghana, efforts including 'Know Your Status' campaign have been made to increase awareness and improve the uptake of HIV screening.

Objective: This study examined the acceptance and utilization of the HIV/AIDS 'Know Your Status' campaign and determine dthe differences in HIV testing by demographic characteristics among the youth in Techiman, Ghana.

Method: This study was a cross-sectional study conducted among the youth aged 15-24 years. A structured questionnaire was used to collect data from 200 purposively selected respondents.

Results: The mean age of the respondents was $19.6 \pm 2.72$ years. There was a universal awareness (100\%) of HIV/AIDs, and were knowledgeable about the mode of transmission, symptoms and the prevention of HIV. A high proportion of the respondents $(n=161,80.5 \%)$ had heard about the 'Know Your Status' (KYS) campaign. Less than half of respondents $(n=91,45.5 \%)$ had tested for HIV, and only 16.5\% ( $\mathrm{n}=15 / 91)$ of respondents tested through the KYS campaign. Testing for HIV was associated with age $(\mathrm{p}<0.001)$ and marital status $(\mathrm{p}<0.001)$.

Conclusion: The youth should therefore be targeted in the awareness and the 'Know Your Status campaigns', and in an effortsto promote screening for HIV.

Keywords: Awareness, campaign, knowledge, HIV/AIDS, know your status, screening.

DOI: https://dx.doi.org/10.4314/ahs.v20i1.19

Cite as: Asare BYA, Yeboaa HY, Dwumfour-Asare B. Acceptance and utilization of HIV testing among the youth: a cross-sectional study in Techiman, Ghana. Afri Health Sci. 2020;20(1):142-9. https:// dx.doi.org/10.4314/abs.v20i1.19
\end{abstract}

\section{Introduction}

Human Immunodeficiency Virus (HIV) causing Acquired Immune Deficiency Syndrome (AIDS) is still a key public health problem, causing over 35 million deaths worldwide ${ }^{1}$ since the beginning of the pandemic. The sub-Saharan Africa is the hardest hit - in 2016, 25.6 million out of 36.7 million people estimated to be living with

\section{Corresponding author:}

Bernard Yeboah-Asiamah Asare,

Research Web Africa,

P. O. Box 2591,

Sunyani-B/A, Ghana;

Mobile: +233(0)200382232;

Email: asiamahyeboah2006@yahoo.com
HIV came from Africa, and for the 1.8 million global new infections, two thirds of them were in Africa ${ }^{1}$.

Global prevention and treatment programs have helped decrease the number of people getting infected and dying from HIV/AIDS every year ${ }^{2}$, but lack of knowledge and misconstruction still poses a challenge to the plans of ending AIDS $^{3}$. Several people infected with HIV are unaware of their status and about $54 \%$ of them require treatment ${ }^{3}$. At present, only $70 \%$ of people infected with HIV globally are aware of their status, well below the set target of $90 \%{ }^{1}$. Several countries have shown commitment to achieving the $90 \%$ target of HIV status awareness by $2020^{3}$. The approach is by adopting the World Health Organization (WHO) authorized range of testing for one's HIV sero-status including "the routine offer of cited.
} 
testing in clinical settings, index partner and family testing, and community- and home-based testing, including self-testing"4. HIV testing is vital for almost all HIV/ AIDS prevention and treatment programs, and such programs are greatly hampered by the gap in the detection of HIV status ${ }^{4}$.

Ghana in 2016 recorded an estimated HIV prevalence of $1.6 \%$ in adults aged $15-49$ years, and status awareness level of only $45 \%$ among people living with $\mathrm{HIV}^{5}$. The country has therefore embarked on several campaigns in its efforts of raising awareness and getting people to test for HIV sero-status under the National AIDS Control Program of the GhanaAIDS Commission. One of the three ways currently available for testing is the 'Know Your Status' (KYS) campaign. The KYS is an outreach program which was initiated in 2007 in all the 10 regions of Ghana to encourage the general population (adults aged 15 years and above) to test for their HIV sero-status ${ }^{6}$. These community based approaches to HIV counseling and testing are seen as innovative ways of spreading the coverage of HIV testing ${ }^{7}$ and there is the need for rigorous evaluation of the effectiveness of these approaches particularly in detecting high HIV positives ${ }^{6}$.

With young people regarded as the centre of the HIV epidemic in terms of new infections ${ }^{8}$, the objective of this study was to examine the acceptance of the KYS campaign and HIV testing, and to determine the differences in testing for HIV by demographic characteristics among adolescents and young adults aged 15-24 years in Techiman the capital of the Techiman Municipality of the Brong Ahafo region. The findings of this study could inform the evaluation and needed improvement to HIV testing and counseling through the KYS campaign among adolescents and young adults.

\section{Methods}

\section{Study design and setting}

This is a cross-sectional study conducted from January to February 2012, at Techiman. Techiman is the capital of the Techiman Municipal Assembly in the Brong Ahafo region. According to the 2010 Population and Housing Census, the Municipality has a total population of 147,788 , with $20.8 \%$ of them aged $15-24$ years 9 . The main economic activity of the people is agriculture, and they are mostly of the Akan (Bono) ethnicity?

\section{Study population and sample}

The study was conducted among adolescents and young adultsaged 15 to 24 years who resided in Techiman. A convenient sample of 200 adolescents and young adults who were willing to take part in the study were purposively recruited. Four suburbs of Techiman namely; Teko, Zongo, Kenten and Nkwaeso were randomly selected and 50 youth each from these suburbs were purposively recruited into the study.

\section{Data collection}

A structured questionnaire was administered through face-to-face interviews to collect data. The questionnaire collected data on the socio-demographic characteristics, awareness and knowledge on mode of transmission of HIV/AIDS, symptoms of HIV/AIDS, preventive measures and availability of treatment for HIV/AIDS; awareness and acceptance of KYS campaign; and HIV testingstatus.Awareness of KYS campaign was defined as ever heard of the KYS campaign; and acceptance and utilizationof KYS campaign was measured as having being tested for HIV sero-status through the KYS campaign.

The study was approved by the Institutional Review Board of the Catholic University College-Ghana. A written and/or verbal informed consent was obtained from respondents aged 18 years and above, and the parents/ guardians of those who were aged below 18 years. Participation in the study was voluntary and codes were assigned to all participants to maintain confidentiality and anonymity.

\section{Statistical analysis}

Data entry and analysis were done using STATA version 12. Descriptive statistics were used to summarize the results into tables and proportions. Chi-square was done to determine the differences in testing for HIV by demographic characteristics. $\mathrm{P}<0.05$ was considered for statistical significant.

\section{Results}

\section{Background characteristics of the respondents}

Table 1 shows the characteristics of the respondents in the study. The study involved 200 respondents aged from 15 to 24 years (mean age $19.6+2.72$ ) and were mostly aged between 20 and 24 years $(n=115,57.5 \%)$. Most of the respondents were females $(n=108,54.0 \%)$ and a high proportion of them were Christians ( $n=174,87 \%)$. Ap- 
proximately $94 \%(n=187)$ of them had formal education and more than half of the respondents were still students $(\mathrm{n}=118,59 \%)$. A high number of respondents $(\mathrm{n}=180$, $90 \%)$ were not married.

\section{Table 1: Background characteristics of the respondents}

\begin{tabular}{lll}
\hline Characteristic & Frequency & Percent \\
\hline Age in years & & \\
$15-19$ & 85 & 42.5 \\
$20-24$ & 115 & 57.5 \\
Sex & & \\
Male & 92 & 46.0 \\
Female & 108 & 54.0 \\
Educational status & & \\
Formal education & 187 & 93.5 \\
No education & 13 & 6.5 \\
Occupation & & \\
Student & 118 & 59.0 \\
Employed & 48 & 24.0 \\
Unemployed & 21 & 10.5 \\
Religion & & \\
Christian & 174 & 87.0 \\
Islam & 26 & 13.0 \\
Marital status & & \\
Married & 20 & 10.0 \\
Not married & 180 & 90.0 \\
\hline
\end{tabular}

\section{Awareness and knowledge on HIV/AIDS}

Table 2 presents the awareness and knowledge on HIV/ AIDS among the study respondents. There was a universal awareness $(100 \%)$ of HIV/AIDs. Most of the respondents indicated HIV is transmitted through sex $(n=135,67.5 \%)$ whereas a quarter of them $(n=50,25 \%)$ indicated through blood transfusion. A third of the re- spondents ( $\mathrm{n}=150,75 \%)$ indicated consistent weight loss and around a quarter of them $(n=58,29 \%)$ indicated opportunistic disease infection as the symptoms of HIV/ AIDs. The use of condoms $(n=134,67 \%)$ and abstinence from sex ( $\mathrm{n}=98,49 \%)$ were mostly indicated as ways of preventing HIV/AIDs transmissions. More than half of the respondents $(n=128,64 \%)$ indicated that there was treatment for HIV/AIDs (Table 2). 
Table 2: Awareness and knowledge on HIV/AIDS

\begin{tabular}{lll}
\hline Statement & Frequency & Percent \\
\hline Heard about HIV/AIDs & 200 & 100.0 \\
Mode of transmission* & & \\
Through sex & 135 & 67.5 \\
Blood transfusion & 50 & 25.0 \\
Sharing of sharp objects & 30 & 15.0 \\
Mother to child & 22 & 11.0 \\
Don't know & 10 & 5.0 \\
Symptoms of HIV/AIDs* & & \\
Consistent weight loss & 150 & 75.0 \\
Opportunistic disease infection & 58 & 29.0 \\
Don't know & 20 & 10.0 \\
Prevention of HIV/AIDs* & & \\
Sex abstinence & 98 & 49.0 \\
Condom use & 134 & 67.0 \\
Avoid sharing sharp objects & 24 & 12.0 \\
Avoid having multiple sexual partner & 7 & 3.5 \\
Don't know & 10 & 5.0 \\
Availability of treatment for HIV & & \\
Yes & 128 & 64.0 \\
No & 72 & 36.0 \\
\hline *mutiple responses given
\end{tabular}

*multiple responses given

Awareness and patronage of the HIV testing and the Know Your Status campaign

Table 3 shows the awareness and patronage of Know Your Status campaign. A high proportion of the respondents ( $\mathrm{n}=161,80.5 \%)$ had heard about the know your status' campaign and of these, approximately 93\% ( $n=150 / 161)$ of them indicated that the aim of campaign was to encourage testing for HIV. More than a third of the respondents $(n=165,82.5 \%)$ indicated to know a facility or place in the municipality for testing HIV, however less than half of them ( $\mathrm{n}=91,45.5 \%)$ had ever tested for HIV and only $16.5 \%(n=15 / 91)$ of them got tested through HIV Know Your Status campaign. Among those who have ever tested, $60.4 \%(n=55 / 91)$ of them indicated that they have been tested once whereas 39.6\% $(n=36 / 91)$ had tested more than once (Table 3). 
Table 3: Awareness and patronage of the HIV Know Your Status campaign

\begin{tabular}{|c|c|c|}
\hline Statement & Frequency & Percent \\
\hline \multicolumn{3}{|l|}{ Heard about the campaign } \\
\hline Yes & 161 & 80.5 \\
\hline No & 39 & 19.5 \\
\hline $\begin{array}{l}\text { Reason for the HIV Know Your Status } \\
\text { campaign }(n=161)\end{array}$ & & \\
\hline Encourage testing for HIV & 150 & 93.2 \\
\hline Don’t know & 11 & 6.8 \\
\hline \multicolumn{3}{|l|}{$\begin{array}{l}\text { Know of any facility or place in the } \\
\text { municipality for testing HIV }\end{array}$} \\
\hline Yes & 165 & 82.5 \\
\hline No & 35 & 17.5 \\
\hline \multicolumn{3}{|l|}{ Ever tested for HIV } \\
\hline Yes & 91 & 45.5 \\
\hline No & 109 & 54.5 \\
\hline \multicolumn{3}{|l|}{ Number of times $(n=91)$} \\
\hline Once & 55 & 60.4 \\
\hline Twice & 18 & 19.8 \\
\hline Thrice & 8 & 8.8 \\
\hline More than three times & 10 & 11.0 \\
\hline \multicolumn{3}{|l|}{ Grounds for testing $(n=91)$} \\
\hline Voluntary testing at diagnostic center & 49 & 53.8 \\
\hline Marriage requirement & 10 & 11.0 \\
\hline Doctor's request & 17 & 18.7 \\
\hline Through Know Your Status campaign & 15 & 16.5 \\
\hline
\end{tabular}

Differences in testing for HIV by demographic characteristics

Table 4 presents the differences in testing for HIV by demographic characteristics. The chi-square analysis revealed that there were statistically significant differences in the testing for HIV for the age groups $(\mathrm{p}<0.001)$, and marital status $(\mathrm{p}<0.001)$ of the study respondents. 
Table 4: Background characteristics by testing for HIV

\begin{tabular}{llll}
\hline Characteristic & \multicolumn{2}{c}{ HIV testing } & p-value \\
\cline { 2 - 3 } & Ever tested, $\mathbf{n}(\%)$ & Never tested, n(\%) & \\
\hline Age in years & & & \\
$15-19$ & $19(22.3)$ & $66(77.7)$ & $<0.001^{*}$ \\
$20-24$ & $72(62.6)$ & $43(37.4)$ & \\
Sex & $44(47.8)$ & $48(52.2)$ & 0.542 \\
Male & $47(43.5)$ & $61(56.5)$ & \\
Female & & & \\
Educational status & $82(43.9)$ & $105(56.1)$ & 0.076 \\
Formal education & $9(69.2)$ & $4(30.8)$ & \\
No education & & & \\
Occupation & $55(46.6)$ & $63(53.4)$ & \\
Student & $28(45.9)$ & $33(54.1)$ & 0.768 \\
Employed & $8(38.1)$ & $13(61.9)$ & \\
Unemployed & & & \\
Religion & $83(47.7)$ & $91(52.3)$ & 0.106 \\
Christian & $8(30.8)$ & $18(69.2)$ & \\
Islam & & & \\
Marital status & $19(95.0)$ & $1(5.0)$ & $<0.001^{*}$ \\
Married & $72(40.0)$ & $108(60.0)$ & \\
Not married & & & \\
\hline *p $<0.05$ & &
\end{tabular}

\section{Discussion}

The study sought to determine the awareness, acceptance of the Know Your Status Campaign and HIV screening among the youth in the Techiman Municipality. The study found a universal awareness of HIV/AIDS. This finding is in line with the observation made in the study by Agyemang, Buor and Tagoe-Darko ${ }^{10}$ in Ghana, where all the adolescent and young people aged 15-24 years had heard about HIV/AIDS. Our study found the majority of the respondents were knowledgeable on mode of transmission, symptoms and prevention of HIV/AIDS. This is supported by another study in Ghana where senior high school students were generally knowledgeable on nature, mode of transmission and prevention of HIV/AIDS ${ }^{11}$. However, Oppong-Asante and Oti-Boadi ${ }^{12}$ have reported of conflicting knowledge on HIV/AIDS among University students in Ghana. The Ministry of Health through its agencies including the Ghana Health Service, Ghana AIDS Commission and the National HIV/AIDS Control Program has over the years engaged in campaigns aimed at awareness creation and sensitization; as it has been recognized that with the absence of a vaccine and cure, prevention through raising awareness and sensitizing the populace is the paramount way of dealing with the HIV/AIDS deadly disease ${ }^{11}$. It has also been established that higher HIV mass communication campaigns exposure is associated with enhanced knowledge on HIV and reduced HIV/AIDS stigma ${ }^{13}$. This could explain the high awareness and knowledge on HIV/AIDS observed in our study.

The study found that the majority of therespondents had heard about the KYS Campaign and knew the reason for the campaign. The KYS campaign was introduced in 2007 by the National HIV/AIDS Control Program with the aim of encouraging testing for HIV sero-status in the general population ${ }^{6}$. This campaign has been part of the general awareness creation and could explain the observed high awareness on the KYS campaign. The current study found that more than three-quarters of the respondents $(82.5 \%)$ knew a facility or place in the municipality for testing HIV, comparable to the over 95\% of students who were knowledgeable about where to get an HIV test observed in another study in Ghana ${ }^{14}$. The 
general increased awareness campaigns and high general knowledge on HIV/AIDS observed among the respondents in the current study could elucidate this observation.

The current study found that only $45.5 \%$ of the respondents had tested for HIV sero-status. This finding concurs with the rates of $45.0 \%{ }^{12}$ and $45.4 \%{ }^{14}$ which have been reported among university students in Ghana. Among the youth in Africa, it has been established that the fear of testing positive for HIV $^{15,16}$ and stigmatization ${ }^{17}$ discourage them from getting tested for their HIV sero-status. This could account for the low rate of testing for HIV/AIDS sero-status seen in our study. It was observed in the current study that high awareness and knowledge of HIV/AIDS did not translate into high uptake of HIV screening. This is consistent with the observation made by Taiwo and colleague ${ }^{18}$ among Nigerian youth, and as stipulated by them having high awareness and knowledge does not guarantee the practice of HIV prevention and control measures.

Although there was an observed high level of awareness about the KYS campaign in the current study, only $16.5 \%$ of adolescent and young adults who had tested for HIV were tested through the KYS campaign. The KYS campaign has been rolled out to give equal HIV testing counseling chance for all adults aged 15 years and over, in communities at static places or as mobile testing within the communities outside the health facilities ${ }^{6}$. However, Gadegbeku et $\mathrm{a}^{15}$ have reported in another study in Ghana that the youth preferred to have voluntary counseling and testing site at the hospitals. This could explain the low acceptance and patronage of testing through the KYS campaign as testing are done within the community either than the health facilities.

We assert from this study that age had a relationship with testing for HIV. This finding concurs with that of Fiaveh et $\mathrm{al}^{16}$ where the age of men at the University of Ghana had a significant relationship with HIV counseling and testing. It has been stipulated by Nwachukwu and Odimegwu ${ }^{19}$ that younger youth may have had a shorter sexual engagement and is less knowledgeable on sexual matters than older youth which could explain the differences in HIV screening observed in our current study. Our study revealed that marital status was also found to be significantly related with the screening for HIV, which is consistent to what has been found in South Africa where women who were married were more likely having tested for HIV ${ }^{20}$. Testing for HIV among pregnancy women has become necessary and compulsory in order to halt mother to child transmissions, and furthermore HIV screening has become a requirement for marriages in most settings in Ghana. These could explain the observation made in this current study.

\section{Study limitation}

The study is limited. The findings in this study were drawn from a quantitative convenient sample of 200 young people in the Techiman and due to the non-probability sampling technique used, generalizing the findings to the entire population of youth in Ghana is limited, but could be useful in the context considered.

\section{Conclusion}

It has been established that adolescents and young adults are aware and knowledgeable about HIV/AIDS, and the Know Your Status campaign. However HIV screening uptake through Know Your Status campaign and in general is low, despite adolescents knowing a place where counseling and testing is done. Screening for HIV was related to the age and marital status of the youth.

Adolescent and young adults should be targeted on education of the importance of seeking early treatment through knowing your HIV status of which the Know Your Status campaigns provide an opportunity. In addition to providing accurate information on HIV, interventions should also be aimed at encouraging the youth particularly those not married to test for HIV.

\section{Acknowledgement}

We would like to extend our profound gratitude to all the study participants.

\section{Conflict of interest}

None declared.

\section{References}

1. World Health Organization (WHO). HIV/AIDS. 2017. Retrieved from http://www.who.int/mediacentre/ factsheets/fs360/en/ Accessed 20 Mar 2018

2. United Nations AIDS (UNAIDS). United Nation AIDS data. 2017. Retrieved from http://www.unaids. 
org/sites/default/files/media_asset/20170720_Data_ book_2017_en.pdf Accessed 27 Feb 2018

3. United Nations AIDS. Global AIDS update. 2016. Retrieved from http://www.unaids.org/sites/default/ files/media_asset/global-AIDS-update-2016_en.pdf Accessed 24 Feb 2018

4. World Health Organization. Prevent HIV, test and treat all: Progress report, 2016. 2017. Retrieved from http:// apps.who.int/iris/bitstream/handle/10665/251713/ WHO-HIV-2016.24-eng.pdf Accessed 25 Feb 2018

5. World Health Organization. Ghana HIV country Profile 2016. 2017. Retrieved from http://www.who.int/ hiv/data/Country_profile_Ghana.pdf?ua=1 Accessed 13 Mar 2018

6. Yawson, AE, Dako-Gyeke P, Addo SA, Dornoo BT, Addo NA. Utilization of HIV testing and counseling in Ghana: implications for Universal Coverage. Africa Journal Reproductive Health, 2014;18(1):145-155

7. Matovu J, Makumbi F. Expanding access to HIV voluntary counseling and testing in sub-Saharan Africa: alternative approaches for improving uptake, 2001-2007. Trop Med Int Health 2007;12:1315-22 PubMed .

8. Monaseh R, Mahy M. Young people: the centre of the HIV epidemic. In: David Ross, Bruce Dick, Jane Ferguson (Eds). Preventing HIV/AIDS in young people: a systematic review of the evidence from developing countries: UNAIDS interagency task team on HIV and young people. (pp 15-35). Geneva: World Health Organization; 2006.

9. Ghana Statistical Service. 2010 Population and House Census; District analytical report: Techiman Municipality. Accra: Ghana Statistical Service; 2014. Retrieved from http://www.statsghana.gov.gh/docfiles/2010_District_ Report/Brong\%20Ahafo/TECHIMAN\%20Municipal. pdf Accessed 13 Mar 2018

10. Agyemang S, Buor D, Tagoe-Darko E. The extent of knowledge about HIV/AIDS among young people in the Ejura-Sekyedumase District of Ghana. Journal of AIDS and HIV Research, 2012;4(11):241-247. DOI: 10.5897/ JAHR12.023

11. Appiah-Agyekum NN, Suapim, RH. Knowledge and awareness of HIV/AIDS among high school girls in Ghana. HIV/AIDS - Research and Palliative Care, 2013; $5,137-144$

12. Oppong-Asante K, Oti-Boadi M. HIV/AIDS knowledge among undergraduate university students: implications for health education programs in Ghana. African Health Sciences, 2013;13(2):270 - 277. http://dx.doi. org/10.4314/ahs.v13i2.11

13. Peltzer K, Matseke G. Determinants of HIV testing among young people aged 18-24 years in South Africa. African Health Sciences, 2013;13(4),1012-1020. http://dx. doi.org/10.4314/ahs.v13i4.22

14. Oppong-Asante K. HIV/AIDS knowledge and uptake of HIV counseling and testing among undergraduate private university students in Accra, Ghana. Reproductive Health, 2013;10(17). http://www.reproductive-health-journal.com/content/10/1/17

15. Gadegbeku C, Saka R, Mensah B. Attitude of the Youth towards Voluntary Counseling and Testing (VCT) of HIV/AIDS in Accra, Ghana. Journal Biology, Agriculture \& Healthcare, 2013;3(11)

16. Fiaveh DY, Okyerefo MPK, Fayorsey CK. HIV counseling and testing among men in the University of Ghana: Implications for gender-based HIV and AIDS prevention interventions. Journal of AIDS and HIV Research, 2011;3(5)

17. Yahaya LA, Jimoh AAG, Balogun OR. Factors Hindering Acceptance of HIV/AIDS Voluntary Counseling and Testing (VCT) among Youth in Kwara State, Nigeria. Africa Journal Reproductive Health, 2010;14(3), 138-143

18. Taiwo OM, Osezua C. Acceptance and uptake of HIV counseling and testing by youth corp members in Osun State, Nigeria. International Journal of Asian Social Science, 2013;3(6):1381-1388

19. Nwachukwu CE, Odimegwu C. Regional patterns and correlates of HIV voluntary counseling and testing among youths in Nigeria. Africa Journal of Reproductive Health, 2011;15(2):131-46

20. Venkatesh KK, Madiba P, Bruyn GD, Lurie MN, Coates, TJ, Graym GE. Who gets tested for HIV in a South African urban township? Implications for test and treat and gender-based prevention interventions. Journal of Acquired Immune Deficiency Syndrome, 2011;56(2): 151165. doi:10.1097/QAI.0b013e318202c82c 